\title{
En los orígenes del Diccionario de construcción y régimen de R.J. Cuervo
}

\author{
Ignacio Ahumada, \\ Departamento de Filología Española, Universidad de Jaén
}

\section{English Summary}

The Colombian language scholar R. J. Cuervo worked for a lengthy period on a Diccionario de construcción y régimen or dictionary of grammatical characteristics which he was unable to finish completely. Prior to this, in 1871, he had produced, in collaboration with his fellow countryman V. González Manrique, a set of specimen entries for a dictionary of the Spanish language. This was reproduced in a volume commemorating the centenary of the death of the latter. The availability of such a facsimile, together with the discovery of unpublished materials prepared by Cuervo reopens the question of the relationship between the specimen and the later construction dictionary. Despite their similarity with the later work, it seems probable that the notes were intended for neither, but reflect Cuervo's abiding interest in government and construction. This was evinced in his early work on a Latin grammar which he published in collaboration with the Colombian M.A. Caro in 1867. He also cited approvingly the comments of the Venezuelan grammarian A. Bello who suggested that dictionaries should contain information on régimen [government], or specific syntax, and construcción [construction], or general syntax. Cuervo devoted forty years to work in this area. His Diccionario de construcción y régimen puts into practice this division of grammatical information into general and more specific rules, although being alphabetically ordered by headwords rather than by the virtually unmanageable ordering by government and construction that might have been attempted. Other than the influence of Bello, and of his own Latin grammar, Cuervo's thinking is close to that structuring the Latin grammar of the French scholar J. L. Burnouf, which was translated in Venezuela, used at the University of Caracas and approved by the Ministry of Education. He was inspired to produce his own Latin grammar with Caro and more generally to develop his grammatical ideas by this work, though it is clear that his own contributions far outweigh the original germ. The modern development of grammatical valency theory and its extensive application to some areas of lexicography means that Cuervo's work is of considerable relevance to this day.

1. Cuando se conoce, aunque sólo sea de manera muy general, la labor lexicográfica de R. J. Cuervo (1844-1911), parece inevitable llegar a establecer una relación — si se quiere tenue - entre el Diccionario de construcción y régimen de la lengua castellana (1886-1893) ${ }^{1}$ y la Muestra de un diccionario de la lengua castellana (1871), obra esta última trazada y publicada en colaboración con el también colombiano V. González Manrique. Aun sabiendo que Cuervo dejó sentada la falta de conexión entre ambos trabajos, creo que el lector se siente tentado a esta posible relación al comprobar la diferencia tan sustancial existente entre la parte redactada por Manrique (entradas: l, laberinto, labrar, lebrel, lirio, loto y luz) y la correspondiente a Cuervo (entradas: o, o, ocupar, ojo, oro y oscuro). Mientras que 
en el primero las siete entradas ocupan siete páginas del folleto, en el segundo las seis seleccionadas cuentan veinticuatro. Contrasta, por otro lado, la parquedad de Manrique en cuanto a noticias gramaticales se refiere con la abundancia de este tipo de información en los artículos firmados por Cuervo.

En el «Estudio preliminar» que F. A. Martínez puso a la primera edición (1954) de la obra completa de Cuervo, el primer continuador del DCR entiende - no sin razón-que es indudable la huella de la Muestra en el $D C R$, así como justificable la insistencia de Cuervo en negarla, puesto que las dificultades surgidas en su amistad con Manrique de tal manera lo exigían (Martínez 1987: I, LXXXVI).

Por el contrario, para J. Á. Porto - redactor principal del tercer tomo (letra E) del $D C R$ - los años de trabajo dedicados al proyectado Diccionario de la lengua castellana, entre otras cosas, fueron decisivos para el joven Cuervo como período de adiestramiento en el quehacer lexicográfico (Porto 1980: 59). En el homenaje que la Universidad de Granada promovió en memoria del profesor J. FernándezSevilla, escribía en 1986 el autor de estas líneas:

Cuervo y Manrique, convencidos de que el principio de autoridad da carta de naturaleza a un uso y sabedores de que la lexicografía de su siglo, por lo que hace a las grandes lenguas de cultura, estaba apoyada en citas literarias, concibieron una empresa de gran alcance de la que sólo nos ha quedado a ciencia cierta, un folleto de treinta y una páginas publicado en Bogotá bajo el título Muestra de un diccionario de la lengua castellana (1871). Por lo demás, es difícil deducir qué proyección tuvo en el $D C R$ la experiencia lexicográfica de Cuervo con Manrique — a pesar de la declaración explícita que el autor de las Apuntaciones hace en la Introducción a su Diccionario-, pues, efectivamente, los objetivos de ambos repertorios eran diferentes. Sin embargo, conviene tener presente que tanto la construcción como el régimen son aspectos que aparecen contemplados en la Muestra, sobre todo en la parte de la que Cuervo era directo responsable (Ahumada 1987: 19)².

La impresión facsimilar que el Instituto Caro y Cuervo hizo de la Muestra con motivo del centenario de la muerte de Manrique (1836-1889), así como los nuevos datos que se aportan, no pueden menos que obligarnos a revisar algunas consideraciones y a reafirmarnos en otras. Aparte de la calidad tipográfica con que se nos presenta el facsímil, la edición debe merecer la aprobación general de los hispanistas por cuanto se nos regalan algunos artículos inéditos de Cuervo para la Muestra y se desempolvan opiniones coetáneas que ayudan a conocer el estado en que quedó la labor conjunta de ambos lexicógrafos.

2. A los seis artículos recogidos en la Muestra se añaden ahora cinco más salidos de su pluma: obedecer, obediente, obligatorio, obligar y obnoxio, bien que sin la estructura que rigió para el intento lexicográfico de 1871; resultado, por otra parte lógico, si pensamos que se trata de una redacción trazada sin ánimo de darla a la luz. Por este motivo, y como punto de referencia para nuestro comentario, me ha parecido conveniente y necesario reproducir en un apéndice el artículo que entiendo puede resultar más ilustrativo: obligar ${ }^{3}$.

Tal y conforme aparece estructurado el artículo en el Apéndice, la primera impresión puede llevarnos a creer que está pensado antes para el $D C R$ que para la Muestra, sobre todo si atendemos a la abundante información gramatical que 
precede a cada una de las autoridades y al cambio de lugar que se opera en la etimología, en la comparación de la entrada con las demás lenguas románicas y en las variantes ortográficas cuando las hay. Como es bien sabido, estas notas de información general tienen la misma distribución que en el $D C R$, es decir, al final del artículo, y no al principio como era preceptivo en la Muestra. Ahora bien, a pesar de que los datos precedentes nos lleven a pensar en la estructuración del $D C R$, no creo probable que estemos ante artículos pensados ni para el proyectado Diccionario de la lengua castellana ni para el mismo DCR. Todo parece indicar que se trata de ensayos que intentan perfilar un proyecto lexicográfico muy concreto: el estudio del régimen.

Ante un objetivo tan perfectamente delimitado, suele citarse como punto de partida del DCR — aunque con las debidas precauciones (Porto 1980: 57) — la carta de E. Uricoechea a Cuervo dirigida desde Bruselas el día 4 de febrero de 1872 (Epistolario 1976: 45). ${ }^{4}$ En ella su preceptor y amigo le recomienda que el régimen verbal debería ser objeto de estudio en el proyectado Diccionario de la lengua castellana, cuya Muestra a estas alturas aún no conoce 5 . Lo cierto es que no era necesaria tal recomendación a Cuervo, puesto que el régimen para el sabio bogotano había sido una preocupación constante (cfr. Páramo 1971: 4). Es más, en la Muestra queda contemplado en la medida de lo posible, ya que la selección de entradas no da pie para mucho más (Ahumada 1987: 21). Y, por otro lado, no debe olvidarse que meses antes (septiembre de 1871) M.A. Caro, amigo y colaborador de Cuervo en las tareas gramaticales, había publicado en esta línea una reseña a la Muestra ${ }^{6}$. Para el coautor de la Gramática latina (1867) la presencia de ejemplos en el Diccionario enseña «a consultores bisoños el legítimo régimen y modo como ha de incrustarse la voz en la frase, en combinación con nombres, verbos o partículas» (Caro 1871: 83) ${ }^{7}$,

Tanto una como otra nota sobre la importancia del régimen en los diccionarios, no parece que pasen de ser pura anécdota. Cuervo llega por otros caminos a sentir la necesidad de estudiar las dificultades que entraña la llamada sintaxis individual (Cuervo 1886-1893: I) ${ }^{8}$, caminos que él mismo se encargó de señalar y que en las líneas que siguen voy a tratar de considerar para de algún modo trazar cómo la obra de juventud del maestro lo lleva hacia un diccionario de regímenes y de aquí al Diccionario de construcción y régimen que hoy conocemos.

3. En la Introducción al $D C R$, Cuervo señala los trabajos menores ${ }^{9}$ que se han ocupado con cierto rigor de la sintaxis individual del español, principal objeto de estudio para su Diccionario. En el comentario breve que dedica a cada uno de ellos, no cabe duda alguna sobre la especial predilección por la obra de A. Bello:

Sagaz el segundo [A. Bello] entre todos los gramáticos para deslindar los oficios de las palabras y señalar las más sutiles modificaciones sintácticas, ilustró con maestría admirable y guiado por un criterio altamente científico el uso de muchas partículas, y asentó sólidas bases para el estudio de las construcciones verbales (Cuervo 1886-1893: III). 
Sobre todo si pensamos que el tratamiento que las tres restantes obras hacen del régimen es la simple enumeración de la preposición que rigen «nombres, verbos y adverbios» (Salvá 1988: 558). Aspecto éste del que también se ocupa Bello (1972: número 1192 y siguientes); pero sobre todo es el gramático venezolano quien hace la propuesta teórica:

(1) Por estas muestras puede conocerse la variedad que en orden a las construcciones activas ha presentado y aún presenta la lengua, y la necesidad de estudiarlas en los diccionarios y en el uso de los autores correctos (1972: número 750).

(2) Dejando a los diccionarios la enumeración de los varios significados que toma cada preposición, y de los verbos que las rigen (1972: número 1192).

En esta propuesta, como señala Porto (1980: 4), está implícita la distinción entre sintaxis general y sintaxis particular, de la primera se ocuparía la gramática y de la segunda el diccionario. Indiscutiblemente este planteamiento supone, como es bien sabido, el punto de partida para el $D C R$. En este sentido no debe olvidarse que Cuervo había aprendido gramática en la obra de Bello, y que, precisamente cuando empieza a rondar en el maestro la idea de un diccionario de regímenes (1872) se hallaba en plena labor como editor y anotador de la Gramática que nos ocupa.

Atendiendo a estas dos propuestas teóricas de Bello y a su habilidad para detectar variantes sintácticas, dejemos que Cuervo nos diga qué intenta ser el $D C R$. En ello veremos que responde fielmente a lo expuesto por el gramático venezolano. El DCR se pensó como:

Una obra especial en que se dé luz sobre las palabras que ofrecen alguna particularidad sintáctica, ya por las combinaciones a que se prestan, ya por los cambios de oficios o funciones gramaticales de que son susceptibles, ya por el papel que desempeñan en el enlace de los términos y sentencias. Tales son la razón y el asunto de nuestro libro (Cuervo 1886-1893: III).

La propuesta de Bello y la caracterización breve que hace Cuervo del $D C R$ son una misma cosa: la variedad sintáctica y sus correspondientes matizaciones semánticas deben estudiarse en los diccionarios. Otra cosa es que resulte si científico, insuficiente, recoger bajo cada entrada sólo aquellas particularidades sintácticas que entrañan dificultad, y no todas y cada una de las que es susceptible cualquier registro de los seleccionados como entradas. La variedad sintáctica que Bello destacaba como objetivo de las obras lexicográficas son las particularidades y dificultades sintácticas de las que habla Cuervo, estudiarlas y establecer el correcto uso de las mismas fue su principal objetivo, actitud ésta, por otro lado, muy provechosa por cuanto acababa de completar con éxito sus conocidas Apuntaciones (1867-1872). De este modo, pasaba de estudiar las particularidades y dificultades del español hablado en Bogotá a un proyecto de mayores logros pero en la misma línea: su «fidelidad al uso de los autores correctos», su preocupación por la norma, y por ende, su preocupación por la unidad de la lengua ${ }^{10}$. Con ello Cuervo intentaba alcanzar dos metas: (a) salir de sus tímidos escarceos de juventud, del localismo propio de los recién iniciados, y (b) zanjar honrosamente su compromiso con Manrique (Muestra, 1871), puesto que se enfrentaba con una obra completamente diferente, por diferente al alcance de cualquier persona con capacidad de trabajo y 
la formación científica necesaria. Mientras que continuar en solitario con el Diccionario de la lengua castellana era una quimera, el Diccionario de regímenes en ciernes podría coronarse con éxito en algunos años.

Lo cierto es que Cuervo, a pesar de su denodado esfuerzo y de restarle cuarenta años de vida, no va a conseguir llegar — en el sentido más pleno - a poder terminar felizmente sus obras más destacadas, pues consagrado casi por entero al $D C R$ durante sus mejores años, sólo atenderá - a excepción de otros trabajos menores - a la revisión de las Apuntaciones; y cuando definitivamente decide abandonar el $D C R$ y dedicarse a su segundo gran proyecto científico: Castellano popular y castellano literario o la refundición de las Apuntaciones (Guitarte 1983), entra en la última etapa de su vida, con lo que las dificultades se agravarían: dejaría inconcluso Castellano popular y cambiaría sustancialmente la edición póstuma (1914) de su obra sobre el lenguaje bogotano.

En definitiva, nos encontramos con un Cuervo que ante un conocimiento profundo de la lengua de nuestros clásicos ha llegado a la conclusión de que, en general, para el correcto uso de la misma conviene recoger en un diccionario todas aquellas construcciones que puedan dar lugar a confusión, y que, por otro lado, no aparecen estudiadas en las gramáticas, puesto que son obras que no se ocupan de este asunto ni tienen por qué hacerlo. Nace de esta manera en 1872 el proyecto de un diccionario de regímenes, cuyos primeros ensayos van a hacerse con materiales pensados para la Muestra y ampliados para este fin, ensayos que - desde mi punto de vista - son los que ofrece la edición facsímil que nos ocupa ([González Manrique-Cuervo-R/] 1989: 61-74).

Cuervo cierra su compromiso con Manrique dando a la luz la Muestra (1871), mas el primero continúa trabajando sobre la misma — como veremos_-, si bien con intereses completamente distintos y sobre materiales acopiados por él y aumentados en los últimos meses. Piénsese que, según testimonios, la recopilación del corpus para el Diccionario de la lengua castellana se inició en 1863 (Gutiérrez 1871: 94), y que median nueve años hasta el proyecto de un diccionario de regímenes. Es posible que los textos seleccionados a lo largo de tantos años fueran de utilidad para la nueva obra, aunque - como confiesa el mismo Cuervo (1886-1893: III) persiguiera objetivos distintos. De no ser por este camino, no tiene explicación en el tiempo el ejemplar anotado de la Muestra que Cuervo remite a Uricoechea con fecha de abril de 1874 y que se conserva en la Biblioteca de la Universidad de Harvard (cfr. González Manrique-Cuervo 1989: 59), cuando —como sabemos - ya en 1872 y a instancias de éste Cuervo se lo había remítido (Epistolario 1976: 6465). El ejemplar anotado de 1874, al que lamentablemente no he tenido acceso, debe de ser la prueba de que el maestro estaba ensayando su proyecto: «Sujetado todo cuaderno y anotaciones, a la consulta de mi erudito y bondadoso amigo D. Ezequiel Uricoechea»; y creo que decide enviárselo - indicándole muy vagamente que se trata de un diccionario de regímenes (cfr. Id.:88-89) - cuando Uricoechea le solicita dos ejemplares de la Muestra para dos amigos de Madrid (Id.: 70), uno de ellos J. M. Sbarbi (Id.: 85). En adelante, las referencias de Uricoechea al 
diccionario de regímenes aparecerán de vez en cuando (Id.:126 y 165), hasta la declaración más explícita en 1876 (1d.: 173-174).

Puede confirmar lo dicho, el apunte que hace Cuervo en la dedicatoria de la Muestra sobre la organización de las acepciones de ojo, criterio de estructuración que luego va a regir para el $D C R$ :

Para el orden de las acepciones creo sería indispensable formar al encabezamiento de cada artículo, una especie de árbol genealógico que diera la clave para la generación de aquellas. Así en ojo, p. ej. hay dos ramas de significados, unos procedentes del radical órgano de la vista, otro de la figura de él: en este caso no están mal eslabonadas; pero con otros casos es indispensable una indicación previa para la cabal inteligencia de las gradaciones de sentido (González ManriqueCuervo 1989: 58).

Sirva como punto final a esta primera consideración cómo en la lista de entradas previstas para el DCR (Porto 1980: 340-345) aparece ojo como entrada propuesta por Cuervo.

4. ¿Cómo, habiendo proyectado Cuervo un diccionario de regímenes, acaba publicando un Diccionario de construcción y régimen? La respuesta nos la da el mismo autor en la Introducción a su obra:

Al intentar esta obra nos ocurrió que bastaba explicar los puntos dudosos comprobándolos con ejemplos de nuestros clásicos: pero la experiencia probó que el camino era errado. Debiendo aparecer cada construcción como resultado de la significación etimológica de los vocablos, rastreada cuidadosamente hasta sus más tenues y delicados desvanecimientos, vimos que era necesario hacer cada artículo tan completo como si hubiese de figurar en el Diccionario general de la lengua (Cuervo 1886-1893: 111).

Y es este el momento que aprovecha Cuervo para aclarar que, aun hablando de artículos propios de un diccionario general, los que se recogen en el $D C R$ nada tienen que ver con un viejo proyecto de diccionario general trazado en colaboración con V. González Manrique, pues los objetivos de ambas obras son bien diferentes. En el Diccionario de Manrique-Cuervo el punto de vista lexicográfico, el principio rector de la microestructura era el estudio del contenido apoyado en autoridades, lo que supone implícitamente — como en cualquier obra lexicográfica — información sintáctica $^{11}$. El $D C R$, por el contrario, tiene su razón de ser en la información gramatical; eso sí, esa información gramatical está supeditada a la información semántica, orden de dependencia que, por otro lado, no podía ser de otra manera. Para su justificación baste pensar en la dificultad que entraña la organización de la microestructura de un diccionario sintáctico atendiendo a criterios de forma, así como el escaso rendimiento que el lector vería en una obra de tales características, $\mathrm{y}$, en último lugar, baste pensar que nos encontramos en pleno auge del historicismo y del desarrollo científico de la etimología como disciplina lingüística, principios ambos que orientan el DCR (cfr. Cuervo 1886-1893: XII).

Al tener que recurrir Cuervo al artículo total, a la monografía - según Freund y Littré (Cuervo 1987: 344) - y no a la exclusiva enumeración de dificultades sintácticas, el filólogo colombiano no puede mantener el título parcial de 
diccionario de regímenes, puesto que no responde al contenido real de la obra. Es entonces cuando echa mano de la distinción entre sintaxis general y sintaxis particular. Con el nuevo planteamiento cada artículo recoge no sólo los «puntos dudosos», sino también todos aquellos de carácter general que le corresponde a la entrada como categoría funcional del sistema lingüístico. La doble perspectiva en que se sitúa ahora el lexicógrafo, obliga a reajustar el título: de la sintaxis general nace construcción; de la sintaxis particular, régimen.

La distinción que da pie al título Diccionario de construcción y régimen era tan familiar a Cuervo como la misma Gramática de Bello. Se trataba de una distinción tan arraigada en sus presupuestos metodológicos que era impensable llegara a ser de otra manera. Cuervo - y con él Caro- había concebido su Gramática de la lengua latina (1867) partiendo de la misma oposición, y el éxito de la obra confirmaba la utilidad del planteamiento. Para esta ocasión, M. A. Caro y R. J. Cuervo habían tomado como modelo la obra de J. L. Burnouf, Método para estudiar la lengua latina (Caracas 1849) ${ }^{12}$, una traducción española del francés original hecha por M. A. Carreño y M. Urbaneja. El texto de Burnouf para la enseñanza del latín venía a Hispanoamérica — concretamente a Venezuelaavalado por un merecido prestigio, de tal modo que fue adoptado por la Universidad de Caracas y la Dirección General de Instrucción Pública? ${ }^{13}$.

En líneas generales, la Gramática de la lengua latina es adaptación de la obra de Burnouf; sin embargo, pueden señalarse sobradamente puntos de comparación donde se hace gala del fino análisis y de la delicada intuición de Caro y Cuervo. Para J. Páramo, a cuyo cargo estuvo la última edición moderna, se trata antes de una reelaboración del trabajo de Burnouf que de una adaptación para hablantes de español. Nítidamente se detecta un punto de vista diferente, marcado, eso sí, por la doctrina gramatical de Bello; sin sustraerse, por otro lado, a la comparación de ambas lenguas, principio muy al uso en los años que corren (cfr. Páramo 1972: XI). Por el contrario, el punto de partida metodológico que aquí interesa, la distinción entre sintaxis general y sintaxis particular, queda inalterado. Desde el prólogo a la primera edición (1867), se deja constancia del rendimiento pedagógico que reporta la separación de los dos tipos de información sintáctica. Con sólo correcciones de estilo en la tercera edición (1876), se nos presenta la redacción definitiva en la cuarta edición o de 1886, cuyo texto transcribo a continuación:

Siguiendo una práctica autorizada, los autores de esta gramática han dividido la sintaxis en general o de construcción, y particular, o de régimen. Explica la primera en comprensivas generalizaciones el mecanismo de la oración; la segunda desenvuelve los mismos principios y analiza giros excepcionales. Esta división lógica, calculada para entendimientos algún tanto cultivados, no es la más conveniente para los principiantes, que naturalmente proceden de lo particular a lo general, y por analogía, ajustando a las fórmulas que primero aprendieron, como a un tipo, los casos semejantes. El alumno que se halle en disposición de ejercitar la memoria más bien que el raciocinio, circunscriba su estudio de sintaxis general a los capítulos I, IV, VI, VIII y X, y pase inmediatamente al de la particular (Caro-Cuervo 1972: 20-21).

Consideraciones, por otra parte, que cuando Burnouf va a centrarse en la sintaxis particular del latín, refleja en los términos siguientes: 
Nous avons montré comment les mots s'unissent pour former d'abord des propositions isolées, puis des phrases composées de plusieurs propositions réunies. Les regles générales ainsi établies, il nous reste á parcourir les principaux faits de syntaxe qui en dérivent ou qui s'en éloignent. Ce deuxieme livre contiendra donc le développement des principes déjá connus, et les exceptions apparentes ou réelles dont ils sont susceptibles (cita tomada de Briceño 1972: 13).

5. La obra lexicográfica de Cuervo no deja de sorprendernos a pesar de los avances y el perfeccionamiento metodológico logrado por la lingüística moderna. Si ya en otra ocasión (Ahumada 1987) destacábamos su originalidad indicando el régimen lexemático en las definiciones lexicográficas, notación de obligado cumplimiento en los diccionarios actuales; en este trabajo los datos que hemos manejado nos permiten ver el progresivo perfeccionamiento de su obra más importante, el Diccionario de construcción y régimen de la lengua castellana. Poder trazar, aunque sólo sea de manera aproximada, el camino seguido por Cuervo para llegar a esta obra monumental que es el $D C R$, nos permite, a la vez que conocer la evolución de su pensamiento, de su método, reafirmarnos en la vigencia de sus planteamientos, puesto que si se ha querido ver en la vieja distinción entre sintaxis general y particular estrecha relación con los conceptos generativistas de sintaxis gramatical y léxica respectivamente (Porto 1980: 3-14), el paulatino acercamiento de Cuervo al estudio pormenorizado del régimen, y de aquí la construcción, no puede menos que llevarnos a entender sus planteamientos como un exponente temprano y certero de los actuales diccionarios de valencias.

\section{$\underline{\text { Referencias bibliográficas }}$}

Ahumada, I. (1987): «Contorno de la definición verbal y régimen lexemático: su indicación formal en la lexicografía hispánica» in Amistad a lo largo. Estudios en memoria de J. Fernández-Sevilla y N. Marín López. Granada: Servicio de Publicaciones de la Universidad de Granada, 13-25.

- (1988): «La información gramatical implícita en la definición lexicográfica» in Thesaurus. Boletín del Instituto Caro y Cuervo, XLIII, 81-94.

- (1989): Aspectos de lexicografía teórica. Granada: Servicio de Publicaciones de la Universidad de Granada.

Bello, A. (1972): Gramática de la lengua castellana destinada al uso de los americanos (1847), prólogo de A. Alonso. Caracas: Ministerio de Educación.

Briceño Jáuregui, M. (1972): «La gramática latina de Caro y Cuervo» in Thesaurus. Boletín del Instituto Caro y Cuervo, XXVII (Separata).

Burnouf, J. L. (1849): Método para estudiar la lengua latina, traducción de M. A. Carreño y M. Urbaneja. Caracas.

- (1857): Méthode pour étudier la langue latine. París: Imprimerie et Libraire classique

de Jules Delalain.

- (1878): Méthode pour étudier la langue latine. París: Imprimerie et Libraire Classique de Jules Delalain. 
Caro, M. A. (1871): «Diccionarios castellanos» in González Manrique-Cuervo 1989: 79-84.

Caro, M. A. y Cuervo, R. J. (1972): Gramática de la lengua latina para uso de los que hablan castellano, edición de J. Páramo Pomareda. Bogotá: Instituto Caro y Cuervo, $10^{\text {a }}$ edición.

Cuervo, R. J. (1886-1893): Diccionario de construcción y régimen de la lengua castellana, edición facsimilar. Bogotá: Instituto Caro y Cuervo, 2* edición 4 tomos.

- (1987): Obras. Bogotá: Instituto Caro y Cuervo.

Epistolario. (1976): Epistolario de E. Uricoechea con R. J. Cuervo y M. A. Caro, edición, introducción y notas de M. Germán Romero. Bogotá: Instituto Caro y Cuervo.

González Manrique, V. y Cuervo, R. J. (1989). Muestra de un diccionario de la lengua castellana, impresión facsimilar de la edición de 1871, ed. de M. Germán Romero. Bogotá: Instituto Caro y Cuervo.

Guitarte, G. L. (1983): «El camino de Cuervo al español de América» in Philologica hispaniensia in honorem M. Alvar, I. Madrid: Gredos, 243-318.

Gutiérrez, V. I. (1871): «Una grande obra» in González Manrique-Cuervo 1989: 9395.

Martínez, F. A. (1987): «Estudio preliminar» (1954) in Cuervo 1987.

Páramo Pomareda, J. (1971): «Una carta inédita de Cuervo y el origen de las Apuntaciones» in Thesaurus. Boletín del Instituto Caro y Cuervo, XXVI (Separata).

— (1972): «Estudio preliminar» in Caro-Cuervo 1972: IX-CIl.

Porto Dapena, J. Á. (1980): Elementos de lexicografia. El 'Diccionario de construcción y régimen' de R. J. Cuervo. Bogotá: Instituto Caro y Cuervo.

- (1988): «Notas lexicográficas: la información sintáctica en los diccionarios comunes» in Lingüística española actual, X, 133-151.

Salvá, V. (1988): Gramática de la lengua castellana según ahora se habla (1830), estudio y edición de M. Lliteras. Madrid: Arco-Libros, 2 tomos.

\section{Apéndice}

En la recomposición lexicográfica de este artículo he procurado ajustarme en la medida de lo posible a la redacción manuscrita y a la microestructura del mismo deducible de la Muestra. En esencia, mi labor se ha limitado a redistribuir las autoridades bajo las acepciones correspondientes, siguiendo la numeración marcada por R. J. Cuervo.

Obligar. v.r. 1. Ligar, prender con lazo (poético y de raro uso).

«O la extranjera grulla en lazo obliga.» León, trad. Hor. Ep. 2 (en el texto captar) 37. $35^{2}$.

«Mira, Padre amoroso, | Cuánto es tenaz esta mundana liga, | Y cómo el engañoso | Contrario con mil lazos nos obliga» León, trad. del Bembo $\left(37.39^{1}\right)$,

2. Compeler moralmente como a cosa de forzoso cumplimiento. 
— Ácus. de pers.: «Para entonces os prometo mi favor y ayuda, como me obliga mi profesión.» Cerv. Quij. 1. 52 (3981).

- Acus. de pers. y compl. con a: «Oblíganos, pues, este precepto a que ni con obras ni con palabras, ni aun con el pensamiento, seamos perjudiciales ni dañosos a nuestros prójimos.» Granada, Comp. de la Doctr. Crist. pte. 2, cap. 6 (11. 104 ${ }^{1}$ ),

- Sin acus. de pers.: "A mucho obligan las leyes de la obediencia forzosa, pero a mucho más las fuerzas del gusto.» Cerv. Pers. 4. 1. $\left(662^{2}\right)$.

«Mucho os pido, pero $a$ más obliga la deuda de responder a lo que la fama de vuestra nación pregona.» Cerv. Nov. 10 (216 $\left.{ }^{1}\right)$.

- Participio: «Nunca en aquel instante de acometella [la aventura] se acuerdan de encomendarse a Dios, como cada cristiano está obligado a hacer.» Cerv. Quij. 1.13 $\left(279^{1}\right)$.

«Decís y aun queréis que esté yo obligada a amaros.» Id., ib. 1.14 (282 $\left.{ }^{1}\right)$.

«No temieron la plaga sino el parecerles que estaban obligados a remediarla.» Quev.

— Con elipsis del a (véase que): «Yo haré lo que soy obligado.» Cerv. Quij. 1.29 $\left(331^{1}\right)$.

«Nosotros [somos] tan negligentes en hacer de nuestra parte lo que somos obligados para disponernos a la gracia, que por maravilla se halla quien cumpla estos mandamientos.» Granada, Comp. de la Doctr. Crist. pte. 2, cap. $10\left(11.153^{1}\right)$.

a) Ser obligatorio o de forzoso cumplimiento.

«Es algo diferente la obligación destas dos maneras de preceptos, porque los afirmativos obligan siempre, en este sentido: que nunca es lícito hacer contra ellos; mas no nos obligan a que siempre estemos en la activa ejecución de lo que significan; diciendo que obligan siempre, mas no por siempre, como se declara por este ejemplo. Este mandamiento: Honrarás padre y madre obliga siempre, porque nunca será lícito quebrantarlo; mas no obliga por siempre, porque no me obliga a estarlos siempre honrando de obras u de palabras, sino cuando fuere menester.» Granada, Comp. de la Doctr. Crist. pte. 2, cap. $1\left(11.93^{1}\right)$.

«Según él [S. Tomás], cuando las leyes son injustas...no obligan en conciencia.» Balmes, Protest. cap. 54 (4, 17, Barcel. 1844).

Éste no es en realidad sino el uso absoluto del verbo, pero la ligera modificación en el sentido exige el dat. de pers.: «A los niños no les obliga el ayuno»; no podría decirse los.

3. Precisar, poner en la necesidad, mover eficazmente, compeler.

- Acus. de pers. y compl. con a: «Mayor era mi necesidad, pues me obligó a comer, lo que él desechaba.» Cerv. Col. $\left(243^{1}\right)$.

«En Sicilia también tomó el pueblo las armas contra el virey (sic) Don Hugo de Moncada, con tanto arrojamiento que le obligó a dejar el reino en manos de la plebe.» Solís, Cong. Méj. $1.4\left(28.211^{2}\right)$.

«La satisfacción que Preciosa le había dado le parecía ser de tanta fuerza, que le obligaba a vivir seguro.» Cerv. Nov. 1 (112 $\left.{ }^{1}\right)$.

«¿Qué reinos ni qué riquezas me pueden a mi obligar a que deje a mi hermana Sigismunda, si no es dejando yo a Persiles?» Id. Pers. 2 . 6 (59). 
«Rey que pelea y trabaja delante de los suyos oblígalos a ser valientes.» Quev. Polit. de Dios, p. 1. c. $6\left(23.17^{1}\right)$.

- Sin acus. de pers.: «La esperanza del premio obliga al respeto, y el temor de la pena a la obediencia.» Saav. Emp. $23\left(25.64^{1}\right)$.

«Cuando es tan evidente el peligro que obligue a la defensa y conservación natural, se le han de cortar las raíces para que no pueda renacer.» Id. ib. $41\left(25.104^{2}\right)$.

«Tal al fin era toda, que obligaba a amor y respeto.» Quev. Casa de locos (Sancha, 2. 24; Riv. convidaba, 23. $351^{1}$ ).

- Met. Con acus. de cosa: «Mas jay! que entre tantas penas, | Cual cedro a humildes artistas, | Hay una que a todas vence | Y a enmudecer las obliga.» Lista, Poesías (67. $\left.348^{1}\right)$.

- Participio. [Ø]

Obligar que es construcción común en los buenos tiempos, pero hoy inaceptable: «Obligasme, cruel, que a mí despecho | Procure contrastar tu fiero intento.» Herrera, Rimas, 1. 2, son. $53\left(32.313^{2}\right)$.

«No de otra suerte que en sereno día | Balas de nieve escupe, y de los senos | De las nubes relámpagos y truenos | Súbita tempestad en monte y prado | Obligando que el tímido ganado | Atónito se esparza.» Lope, Gatom. Silva 1 (38. 436 ${ }^{1}$ ) (En la silva 2: «Obligando a que tome | Un palo algo criado.»440 ${ }^{1}$ ).

«No se fió del pueblo ni del Senado; antes obligó que el senado y el pueblo fiasen de su determinación sus agravios.» Quev. Marco Bruto (23. 159 ${ }^{1}$ ).

«Tus semblantes ceñudos y mohinos, | Si no descifran Délfica respuesta, | Obligan que de risa descompuesta | Se descalzan los propios Calepinos.» Id. Musa 2, son. 93 (69. $\left.30^{2}\right)$.

4. Poner, mediante demostraciones de respeto o cariño en el caso de ser grato, accesible o indulgente; captarse la voluntad.

- Absol.: «Manifestó luego su regalo, como quien obligaba para ser admitido y ponía la liberalidad al principio del rendimiento.» Solís, Conq. Méj. 1.20 (28. 229²).

- Con acus. de pers.: «Conoció Germánico este odio y que con especie de honor le retiraba de las glorias de Alemania, y procuró obligarle [a Tiberio] más con la obediencia y sufrimiento.» Saav. Empr. $47\left(25.119^{1}\right)$.

«Aunque más la obligue, y se muera queriéndola, y le haga todas las buenas obras que pueda, y tenga todas las gracias de la naturaleza juntas, no terná fuerza la voluntad.» Sta. Ter. Cam. Perf. 6 (Falta el verbo en Rivad. 53. 327, cap. 10).

«Amalde, si vos me amáis; | Que con eso me obligáis.» Lope, Querer la propia desdicha, 2.1. (34. $\left.376^{1}\right)$.

«Ellos que me vieron largo en lo de la merienda, aficionáronseme, y por obligarme me implicaron cenase con ellos aquella noche.» Quev. Gran Tac. 19 (23. 518²).

«Han a mi desdén más fuerza | La discreción que el amor, | Y me obligáis más con ella.» Moreto, El Desdén, 2.4 (39. 11 $\left.{ }^{1}\right)$.

- Refl.: «Plegue a Dios que se obligue | De ver que ha venido a verla.»Cald. Guárdate de la agua mansa, 2. 5 (9.386 $\left.{ }^{3}\right)$.

- Participio: «Como convencida y obligada a los muchos servicios de Elicio, con algún honesto favor le subía al cielo.» Cerv. Gal. $1\left(3^{1}\right)$. 
«Con menos que por mí hicieras, te quedara perpetuamente obligada.» Id. ib. $4\left(50^{1}\right)$.

«Puso en él [el bajel] cincuenta soldados, todos amigos y conocidos suyos, a quien él tenía obligados con muchas dádivas y promesas.» Id. Nov. 2 ( $\left.131^{1}\right)$.

«Don Fernando, caballero ilustre, discreto, obligado de mis servicios.» Id. Quij. 1. 27 $\left(321^{2}\right)$.

5. Empeñar, dar en prenda (anticuado).

«Ca si un ome pidiesse dineros prestados a otro sobre alguna cosa que él diesse a peños, e ficiesse carta sobre sí, o se obligasse de otra manera a pagarlos enantes que oviesse recebido aquellos dineros, e después obligasse aquella cosa misma a otro recibiendo luego los dineros de aquel a quien a postremas la obliga, magüer aquel a quien primeramente fuesse obligada la cosa pagasse después aquello que avía prometido a emprestar sobre ella, fincaría obligada la cosa a aquel que fue después empeñada.»Part. 5, t. 13, 1. 27.

- Participio: «Aquella posesión era suya realenga, libre de todo censo perpetuo y al quitar, y no hipotecada ni obligada por otra deuda.» Alemán, Alfarache.

Fuera de la construcción obligar una cosa a otro se halla también obligar una cosa a otra a peños (ibid., 1. 23), que imita más fielmente la frase del Digesto, obligare omnia bona sua pignori. Freund, s.v.

- Met. «¿Vuestra palabra real | Obligáis justo o injusto, | De no recibir disgusto?» Lope, El molino, 3. 19 (24. $\left.46^{2}\right)$.

«Quiero que me obligues | Antes tu fe con juramento estrecho | De estarte a un lado y no moverte un paso | A impedir el efecto de mi intento.» Jáuregui, Aminta, 4 (42. 146 ${ }^{1}$ ). (En el original aparece aquí el verbo legare, ligar, de suerte que el traductor imita más bien la frase latina obligare tuam fidem.).

6. Sujetar, someter, hacer acreedor.

«La culpa nos enemista con Dios... nos sujeta al demonio y nos obliga a penas sin fin.» León, Nombr. 3.

- Con acus. de pers. y compl. con a: «Oh alma mía, mira lo que haces cuando resistes a la voluntad de Dios y a su santa inspiración; ... a ti misma haces gravísimo daño, porque con esa resistencia te haces toda sangre, manchándote con culpas y obligándole a terribles penas.» Puente, Medit. 5. 29.

«Carga de hierro duro | Sus miembros y se obliga | El joven al trabajo de la guerra.» Lup. Argens. Canc. $2\left(42.260^{1}\right)$.

- Refl. «Bueno es el oficio y honra grande, y merced hace el rey a quien le da, mas no se obliga a poco en tomarle.»Sta. Ter. Cam. Perf. 18 (Rivad.: «Por muy poquito más de honra se obligan a padecer mucho más.» 53. $340^{2}$ ).

- Partic. «[Nace nuestra substancia] culpada y enemiga de Dios, y hija de a ira y del demonio y obligada al infiemo.» León, Nomb. 1, núm. 8 (37. 101²).

« Oh condición miserable nuestra, y a cuantos varios y miserables casos estamos obligados!» Alemán, Alfarache.

«Después que por el pecado perdió la justicia, quedó obligado a la ley natural.» Mtro. Venegas, Agon. 2. 1.

7. Comprometerse legalmente, hacerse responsable. 
- Con de: Cv. $689^{1}$ [«Dilo, señor, que desde aquí me obligo de no decir que tú me lo dijiste, le dije, por la fe de buen amigo»].

- Refl. con compl. con a: «La obligación puede ser solidaria aunque uno de los deudores se obligue diferentemente que el otro al pago de la misma cosa.»Dicc. de Legisl.

Ortogr. La $g$ se convierte en gu antes de $e$ : obligue, obligué, obliguemos.

Etim. Lat. obligare, comp. de $o b$, que da la idea de rodear, cubrir y ligare, ligar. Cat. Valenc. Mall. obligar. Port. obrigar. Fr. obliger (Ingl. oblige). It. Obbligare. 


\section{$\underline{\text { Notas }}$}

\footnotetext{
${ }^{1}$ En adelante citado DCR.

2 Similares consideraciones y nuevos datos quedaron recogidos en Ahumada 1989: 121-131, donde se incluye, además, un cuadro comparativo de las definiciones académicas de 1869 y las de la Muestra, añadiéndose otras de diccionarios actuales.
}

${ }^{3}$ Vid. Apéndice.

${ }^{4}$ No debe olvidarse que Cuervo fija el día 29 de junio de 1872 como fecha de inicio del DCR (Porto 1980: 58 y su nota 32).

${ }_{6}^{5}$ La Muestra estaba publicada, al menos, desde el 19 de julio de 1871 (Gutiérrez 1871: 95).

6 «Diccionarios castellanos» (1871), recogida hoy entre los testimonios que se incluyen en la edición facsímil de la Muestra que hoy nos ocupa (Caro 1871).

${ }^{7}$ No debe olvidarse que la falta de ejemplos y/o citas en los diccionarios españoles de la época llevó a Manrique y Cuervo a proyectar su Diccionario.

${ }^{8}$ De los conceptos de sintaxis general y sintaxis particular en Cuervo, así como de su validez en la gramática moderna, se ha ocupado Porto 1980: 3-13.

${ }^{9}$ Opongo trabajos menores a diccionarios dedicados exclusivamente al régimen. Cuervo destaca como sus precedentes en el estudio del régimen — si bien de forma parcial - los trabajos de la Academia, Gramática (1771); G. Garcés, Fundamento del vigor y elegancia de la lengua castellana (1791); y las gramáticas de V. Salvá (1830) y A. Bello (1847).

${ }^{10}$ Además, el plan de la obra estaría muy en consonancia con el tipo de publicaciones que caracteriza la juventud de Cuervo: obras dirigidas a un gran público; si bien su autor reconoce cuando da cuerpo al primer tomo que perfectamente podría llevar su trabajo el epígrafe de Contentis paucis lectoribus (Cuervo 1886-1893: IV). La situación de Cuervo y su familia, como ha señalado Guitarte (1983, 249), era lamentable; de aquí que Uricoechea no conociera bien los avatares del joven Cuervo. Precisamente cuando nuestro hombre le insinúa ciertas dificultades que entraña seguir con el diccionario Uricoechea responde: «¿Qué diablo de dificultades son las que U. me habla? U. no necesita de su tiempo para vivir, tiene lo suficiente para no postergar sus gustos a los reales. ¿Qué le falta? ¿Es que le disgusta el compañero? Creo que tampoco, porque jamás vi caballero más completo que Venancio, ni nunca amigo mejor» (Epistolario X: 55).

${ }^{11}$ Sólo en determinados casos la Muestra, y por ende el Diccionario, abunda en información gramatical (cfr. Ahumada 1987: 20-21). Sobre la información gramatical en los diccionarios modernos, vid. Ahumada 1988 y Porto 1988.

${ }^{12}$ He seguido la edición de Burnouf correspondiente a 1878.

${ }^{13}$ De esta edición de 1849 se sirvieron Caro y Cuervo para proyectar su Gramática de la lengua latina. Es imprescindible la consulta de Páramo 1972: X-XIX y Briceño 1972 para comprender tanto la importancia de Burnouf en los planteamientos de los jóvenes bogotanos como para valorar las aportaciones originales de los mismos. 